\title{
$\begin{array}{ll}\text { Research Square } & \text { Preprints are preliminary reports that have not undergone peer review. } \\ \text { They should not be considered conclusive, used to inform clinical practice, }\end{array}$
}

\section{Lack of Negative Effects of Fasting of Gilthead Seabream (Sparus Aurata) Breeders During the Spawning Period on Maternal and Egg Nutrient Composition, Fertilization Success and Early Embryo/larval Development}

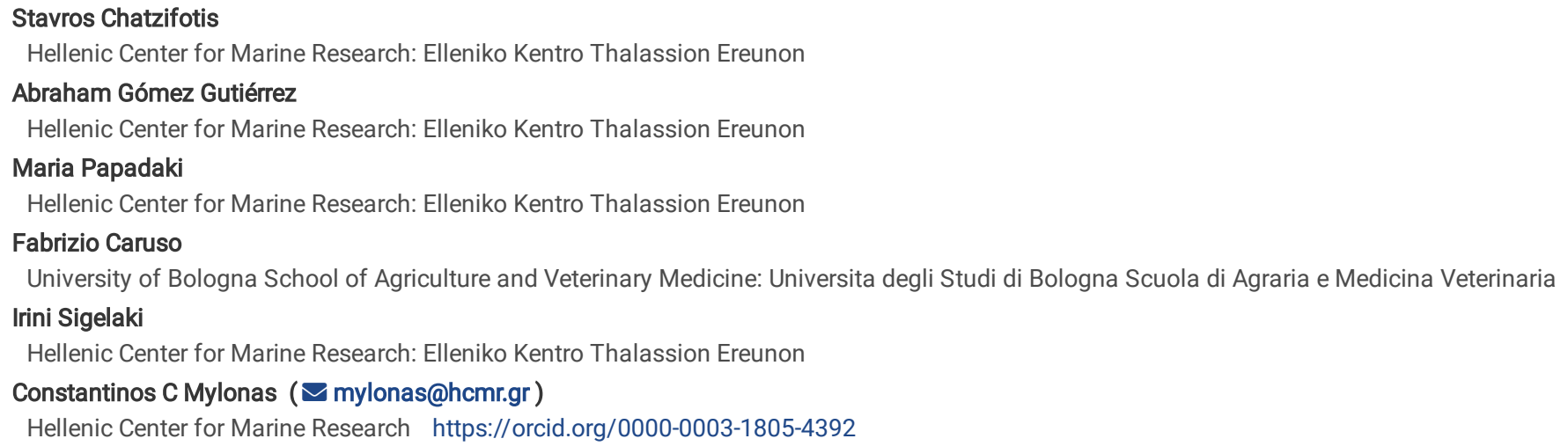

Version of Record: A version of this preprint was published at Fish Physiology and Biochemistry on July 5th, 2021. See the published version at https://doi.org/10.1007/s10695-021-00979-w. 


\section{Abstract}

The effect of fasting on spawning performance, maternal and egg nutrient composition, and on embryo/larval development was monitored in gilthead seabream (Sparus aurata). Two broodstocks were fasted during two consequtive years, for a period of 43 and 54 days withing the spawning season, in a preliminary (year 1) and a main study (year 2), respectively. Mean daily fecundity showed a declining trend during fasting in the main study only, while fertilization success was high in both years and it was not affected by fasting, as was hatching and 5-day larval survival. There was a loss of $23.5 \%$ of maternal body mass due to fasting, and gonadosomatic and hepatosomatic indexes as well as crude protein in maternal muscle and gonads -but not in liver-

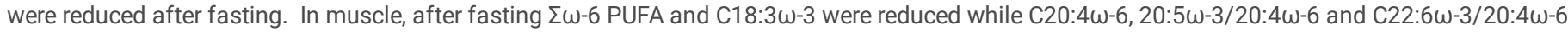
increased; in liver, significant reductions were observed in C16:0, C18:3 $\omega-3,20: 5 \omega-3 / C 22: 6 \omega-3$ and increases in C18:0, C20:5 $\omega-3, \Sigma \omega-6$ PUFA and

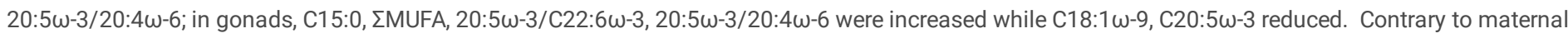
tissues, the energy density and proximate composition of the eggs did not change due to fasting. The study suggests that fasting of gilthead seabream breeders for many weeks during the spawning period does not affect spawning performance, egg proximate composition or embryo and early larval development, since maternal nutrient reserves are mobilized to maintain optimal egg nutrient composition.

\section{Introduction}

The gilthead seabream (Sparus aurata) is a prolific marine species and during spawning (Northern hemisphere: December-April) females spawn > 2x $10^{6}$ eggs $\mathrm{kg}^{-1}$ of body weight, resulting in a total egg biomass that exceeds many folds the body weight of the fish (Mylonas et al. 2011). The gametogenic process consists of an oocyte growth phase ( 2 months before spawning) and a maturation-spawning phase (3-4 months) when primary oocytes are continually being recruited for vitellogenesis (asynchronous ovarian development), and batches of post vitellogenic oocytes undergo maturation, ovulation and spawning almost on a daily basis. During reproduction, gilthead seabream continues to feed, albeit with an apparent decrease in voluntary feed intake (Kadmon et al. 1985), and thus the diet is expected to provide the bulk of biomass needed to produce eggs. It has been also suggested that females utilize dietary nutrients for the oocyte growth phase (i.e. vitellogenesis) without depletion of their body nutrients, while muscle and adipose tissue are additional sources of nutrients during the spawning phase (Harel and Tandler 1994).

Although the importance of broodstock nutrition for the production of good quality fry is well recognised (Cerdá et al. 1994a; Cerdá et al. 1994b; FernándezPalacios et al. 2011; Izquierdo et al. 2001; Perez and Fuiman 2015; Tandler et al. 1995), little is known about the effect of feeding ration on nutrient and energy allocation for growth, maintenance and reproduction in spawning gilthead seabream. This is because various parameters present unique challenges to broodstock nutrition research. Firstly, nutrients for gonadal development can be obtained either from the feed or from resources deposited in tissues long time before spawning, and the breeding cycle itself may affect nutrient acquisition. Secondly, feed availability does not simply influence spawning success in terms of directing nutrients towards maturing oocytes; it can be a determinant factor, as in salmonids, where puberty occurs one year before spawning and depending on the available energy resources there is stimulation or inhibition of the brain-pituitary-gonad axis through hormonal action (Roa et al. 2010). Feed availability can also be a modulating factor, as in European sea bass (Dicentrarchus labrax), where a half ration delayed the time of spawning and reduced egg diameter (Cerdá et al. 1994a). Thirdly, the criteria for evaluating nutrient requirements for broodstock are more diverse and not always clearly defined (e.g. larval quality) compared to the usual growth and feed conversion ratio indexes used for fish during nursery or grow-out rearing. Finally, certain nutrients (e.g. carotenoids) may be essential to produce good quality eggs, but they may not be required for growth (Scabini et al. 2011).

In order to ensure optimal egg production in commercial aquaculture, hatchery managers are always concerned with the quality and quantity of feed provided to their broodstocks. Although there is a consensus on the importance of good nutrition during the period of vitellogenesis (Cerdá et al. 1994a; Higuchi et al. 2018; Higuchi et al. 2017), there are few studies on the effect of food ration during the spawning season on reproductive performance of cultured fishes. In the present study, we examined the allocation of body resources to eggs in the gilthead seabream, a highly fecund, multiple spawning species with a long spawning period, using an extreme scenario of total feed deprivation for a period of a few weeks within the annual spawning season. The hypothesis examined was that fasting would eventually affect negatively spawning performance (fecundity and fertilization success), as well as the nutrient composition of eggs and probably embryo survival. The obtained results are expected to provide guidance for better broodstock feeding practices in fish aquaculture.

\section{Materials And Methods}

Our investigation was carried out over two consecutive years, looking at the spawning performance of gilthead sea bream subjected to fasting for a period of time during the spawning season. We carried out first a preliminary study (Year 1), looking only at the effect of fasting on fecundity and fertilization success. Then, in the next year (Year 2) we carried out a main study looking additionallly at the effects on maternal and egg nutrient composition, and on embryo/larval development.

\subsection{Broodstock maintenance}

The study was conducted at the AQUALABS facilities of the Institute of Marine Biology, Biotechnology and Aquaculture (IMBBC) of the Hellenic Centre for Marine Research (HCMR), Heraklion, Crete, Greece, (Registration No EL91-BIObr-03 and EL91-BIOexp-04). Ethical approval for the study was obtained by the relevant Greek authorities (National Veterinary Services) under the license No 255356 (A $\triangle \mathrm{A}: 6 \wedge I 17 \wedge \mathrm{K}-\Pi \wedge \Omega$ ). All procedures followed the "Guidelines for the treatment of animals in behavioral research and teaching" (Anonymous 1998), the Ethical justification for the use and treatment of fishes in research: an update (Metcalfe and Craig 2011), the "Directive 2010/63/EU of the European Parliament and the council of 22 September 2010 on the protection of animals used for scientific purposes" (EU 2010) and the Greek Presidential Decree 56/2013 on "the protection of animals used for scientific purposes". 
Two gilthead seabream broodstocks (broodstock 1 and broodstock 2, Table 1) were maintained in separate 5- $\mathrm{m}^{3}$ tanks, supplied with well seawater (37 ppt) at temperatures ranging from $18.5-20.0^{\circ} \mathrm{C}$ connected to a recirculating aquaculture system (RAS), and were exposed to a simulated natural photoperiod.

Measurements of temperature and water quality (Dissolved Oxygen, $\mathrm{NH}_{3}-\mathrm{N}$ and $\mathrm{NO}_{2}-\mathrm{N}$ ) were conducted once per week throughout the year. Feeding was done 5 days per week to apparent satiation with commercial broodstock feed (Skretting S.A., Spain and IRIDA, S.A., Greece). Both broodstocks were exposed to the same fasting during the spawning season and were used as replicates, and no additional fully-fed control broodstocks was considered necessary. Each broodstock was used as its own control every year, since comparisons were made within both broodstocks among the pre-fasting, fasting and post-fasting states. The introduction of two additional fully-fed control broodstocks could have introduced errors due to breeder variability, unrelated to the feeding regime.

The preliminary study examined only the effect of fasting on spawning performance (fecundity and fertilization success), by monitoring fecundity and fertilization success before, during and after the fasting period. In year 2, the main study monitored also hatching and 5-day larval survival success, as well as maternal (before fasting and after fasting) and egg nutrient content before, during and after the fasting period. We only sampled (i.e. killed) two females from each tank ( $n=4$, before fasting and after fasting), because we did not want to affect greatly the sex ratio and dominance structure of the breeding population, since this could have significant effects on sex reversal of the smaller males in the population, and potentially egg production and fertilization, which would not be related to the hypothesis examined in the study. The female samples were taken on January 9 (the day the fasting started) and on May 12 (the last day of fasting). During the samplings, fish length and weight were measured and their gonads and livers were excised and weighed, for the calculation of the gonadosomatic index (GSI) and the hepatosomatic index (HSI), as follows: GSI=(gonad weight/body weight)*100 and HIS=(liver weight/body weight)*100.

\subsection{Evaluation of egg/larval quality}

At the expected onset of the spawning season (January), a passive egg collector was placed in the outflow of each spawning tank, to collect the spawned eggs. For both the preliminary and main study, spawned eggs were collected every morning ( $18 \mathrm{~h}$ after spawning) into a 10-I bucket and their number (fecundity) was estimated by counting the total number of eggs in a sub-sample of 5 or $10 \mathrm{ml}$ (depending on the total number of eggs) under a stereoscope. Fertilization success was evaluated at the same time by examining the sampled eggs for the presence of viable embryos (usually at the blastula stage).

In year 2 for the main study, in addition to monitoring daily fecundity and fertilization success, we also incubated fertilized eggs to examine embryonic development, hatching and 5-day larval survival. This evaluation was done once a week for 70 days before fasting, 54 days during fasting and 38 days (Broodstock 1) and 79 days (Broodstock 2) after fasting. To monitor embryo and larval survival, eggs were placed individually in 96-well microtiter plates (in duplicates) according to a developed procedure (Panini et al. 2001), with some modifications. Briefly, floating (almost $100 \%$ fertilized) eggs were taken in a $250-\mu \mathrm{m}$ mesh filter and were rinsed with sterilized seawater and poured in a 2-I beaker. A Petri dish was used to scoop 100-200 eggs from the beaker. The Petri dish was then placed under a stereoscope and only fertilized eggs were taken one by one with a micropipette set to $200 \mu \mathrm{l}$ and transferred to the wells of the microtiter plates (one egg per well). The microtiter plates were then covered with a plastic lid, placed in a controlled-temperature incubator and maintained for 5 days at $19 \pm 0.5^{\circ} \mathrm{C}$. Using a stereoscope, embryonic and early larval development was evaluated once a day for 5 days. The number of (a) live embryos was recorded 1 day after egg collection (or $\sim 36 \mathrm{~h}$ after spawning, day 1 ), (b) hatched larvae was recorded 2 and 3 days after egg collection (>60 h after spawning) and (c) viable larvae was recorded 4 and 5 days after egg collection ( yolk sack absorption).

Embryo survival was calculated as the number of eggs having live embryos $1 \mathrm{~d}$ after egg collection / number of fertilized eggs initially loaded in the microtiter plates. Hatching success was calculated as the number of hatched larvae / the number of live 1-d embryos, and 5-d larval survival was calculated as the number of live larvae $5 \mathrm{~d}$ after egg collection / the number of hatched larvae. Estimating percentage survival (\%) by using in the denominator the number of individuals that survived to the previous developmental stage was considered as a more independent evaluation of survival within specific developmental stages, without the potential of a masking effect of the previous stage (Mylonas et al., 1992; Mylonas et al., 2004).

\subsection{Chemical analysis}

For the chemical analysis, we obtained tissues (gonad, muscle and liver) from female breeders before and after fasting ( $n=4)$, as well as eggs (10 g) from various spawns before fasting $(n=12)$, during fasting $(n=16)$ and after fasting $(n=10)$. All tissues/eggs were frozen immediately after collection $\left(-80^{\circ} \mathrm{C}\right)$ and subsequently freeze-dried until analyzed. The dry matter was determined by drying at $95^{\circ} \mathrm{C}$ until contant weight, ash by burning at $600^{\circ} \mathrm{C}, \mathrm{crude}$ lipid by chloroform-methanol extraction (Folch et al., 1957), crude protein by Dumas method ( $\mathrm{N}$ x 6.25) and energy by adiabatic bomb calorimeter. The fatty acid profile was determined after the analysis of methyl esters by gas chromatography. Fatty acid methylesters were prepared according to (AOAC 1989). The chromatography instrument was equipped with a flame-ionization detector and a capillary column $(60 \mathrm{~m} \times 0.25 \mathrm{~mm}$ i.d. $\times 0.15 \mu \mathrm{m}$ film thickness). Helium was used as carrier gas at $2 \mathrm{ml} \mathrm{min}^{-1}$ constant flow; the split ratio was $1: 50$ and the injected volume $1.0 \mu \mathrm{l}$. The thermal gradient was $50^{\circ} \mathrm{C}$ for $1 \mathrm{~min}, 50^{\circ} \mathrm{C}$ to $175^{\circ} \mathrm{C}$

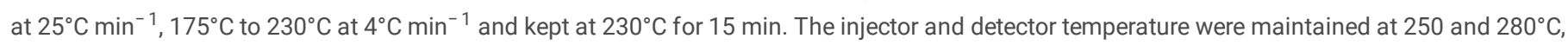
respectively. Fatty acids were identified by comparison with a known standard mixture (Supelco 37 Component FAME Mix). Fatty acid methylester (FAME) contents were expressed as a \% of total FAME.

\subsection{Statistical analysis}

Differences in broodstock biometrics, fatty acid composition of eggs and tissues, proximate composition of eggs, mean relative fecundity, egg development parameters (fertilization success, hatching and 5-d larval survival), fish length and weight, gonad and liver weight and GSI and HSI before, during and after fasting were examined using one-way Analysis of Variance (ANOVA), at a minimum P $\leq 0.05$, followed by Tukey's HSD test at $P \leq 0.05$. Data were examined for normality in the distribution of variances, to comply with the prerequisites of ANOVA. All analyses were performed with a linear statistics software (JMP, SAS Institute Inc., Cary, NC). Results are presented as mean \pm SEM, unless mentioned otherwise.

\section{Results}


Daily egg production during both the preliminary (year 1) and the main study (year 2) exhibited marked variations in both broodstocks (Figs. 1 and 2), representative of the variability in spawning kinetics among sparid broodstocks and over different years (Mylonas et al. 2004; Mylonas et al. 2011; Papadaki et al. 2008), exhibiting a gradual increase in fecundity at the beginning of the season, and a reduction towards the end. Fertilization success was always high, while hatching and 5-day larval survival in both tanks exhibited more variations (Fig. 2).

Mean daily relative fecundity was significantly higher during the periods of fasting and post-fasting during the preliminary study (Fig. 3A), whereas it showed a trend towards decreasing values in the main study (Fig. $\mathbf{3 C}$ ), resulting in significantly lower mean values in the post-fasting period. Mean fertilization success also increased during fasting in the preliminary study (Fig. 3B), but was unchanged in the main study (Fig. 3D). Hatching exhibited a slight increase during fasting, but it decreased significantly in the post-fasting period (Fig. 3E), whereas 5-day larval survival exhibited high and unchanged values throughout the study (Fig. 3F).

After the period of fasting, the sampled females exhibitied a weight reduction of 23.5\% (Table 2). In addition, fasted fish showed reduced GSI and HSI. The body weight loss had an impact on proximate composition of muscle, liver and gonads (Fig. 4). After fasting, there was a significant increase in the water content of all three tissues, a reduction of crude protein concentration in muscle and gonads, but not in liver, and a reduction of crude fat concentration in liver, but not in muscle and gonad. On the contrary, fasting did not affect the ash concentration in any of three tissues studied.

We further investigated the effect of fasting on lipid composition by analysing the fatty acid profiles of lipid extract of muscle, liver and gonads (Table 3 ). In general, fed and fasted fish exhibited a similar profile of muscle fatty acids without significant differences in $\Sigma$ SFA and $\Sigma$ MUFA or $\Sigma \omega-3$ PUFA. In muscle, $\Sigma \omega-6$ PUFA, C18:3 $\omega-3$ were reduced after fasting, while C20:4 $\omega-6, C 20: 5 \omega-3 / 20: 4 \omega-6$ and C22:6 $\omega-3 / 20: 4 \omega-6$ increased. In liver, significant reductions were

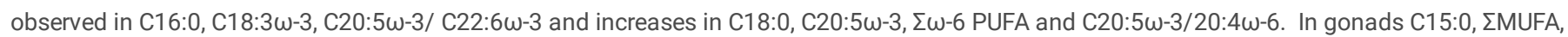
20:5 $\omega-3 / 20: 4 \omega-6,20: 5 \omega-3 / 20: 4 \omega-6$ were increased while $C 18: 1 \omega-9, C 20: 5 \omega-3$ reduced. Overall in all tissues, the differences in numerical values were small, and their biological significance was not apparent.

The proximate composition of eggs was monitored over 125 days of the main study (year 2) with multiple samplings of daily spawns before, during and after fasting (Table 4). Water was the major constituent of eggs, followed by crude protein, lipid and ash with concentrations of ca. $93,0 \%, 3.8 \%, 1.5 \%$ and $1.2 \%$, respectively. The total number of eggs produced during fasting was 29.5 million; total egg biomass was $21 \mathrm{~kg}$, which corresponds to $0.82 \mathrm{~kg}$ crude protein and $0.30 \mathrm{~kg}$ crude fat. Assuming a conservative flesh yield of $42 \%$ prior and $38 \%$ post fasting the total crude protein loss from flesh during fasting was 1.39 $\mathrm{kg}$, exceeding by far the total crude protein release through eggs $(0.82 \mathrm{~kg})$. The energy density $(\mathrm{ca} .1,33 \mathrm{~kJ} / \mathrm{g})$ and the proximate composition of the eggs were stable over the observation period and notable differences were not observed between samples taken prior, during and after the fasting period. Lipid extracts from eggs were also analyzed for their fatty acid profile. The most notable differences were detected in C16:0, C18:0 C18:1 $\omega-9, \mathrm{C} 18: 2 \omega-6, \Sigma \omega-6$ PUFA,

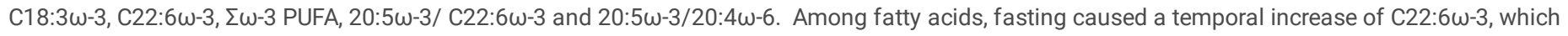
returned to its initial value at the end of fasting. The opposite trend -a decrease- were shown in C18:1 $\omega-9, \mathrm{C} 20: 5 \omega-3, \mathrm{C} 18: 2 \omega-6$ and $\Sigma \omega-6$ PUFA.

\section{Discussion}

A balanced broodstock diet is considered imperative for the achievement of satisfactory egg production, and egg and larval quality in aquaculture. Therefore, specialized and expensive broodstock feeds are produced to ensure proper intake of nutrients, such as proteins, lipids, vitamins and carotenoids. Depending on species, some fish cease feeding during reproductive development and/or spawning, while others reduce their feed intake. In gilthead seabream, although feeding continues throughout the reproductive period, it has been shown that fish use their liver and muscle reserves during this period (Almansa 2001). In the present study, we were interested in investigating whether the energy and nutrients stored in fish tissues are adequate to cover the demands of spawning, and if or how soon diet deprivation may have negative effects on the spawning performance of fish, both in terms of fecundity, but also fertilization success and embryo/larval development. This information may provide guidance for optimal broodstock feeding practices in fish aquaculture.

The preliminary experiment in the present study examined the effect of fasting for 43 days in the beginning of the spawning season on egg fecundity and fertilization success, demonstrating that not only these reproduction parameters were not affected negatively by the fasting, but in fact they increased during and after the fasting period. This might have been because the fasting period started early in the spawning season (February), when fecundity was still in an increasing trend and the nutritional status of the females was still great, and the number of vitellogenic oocytes in their ovaries still high. Based on these surprising results, in the main study that was carried out the next year, fasting begun later in the year, around the middle of the spawning period, and also consisted of a longer fasting period of 54 days. The results, as discussed below, were again similar, in that no negative effects on spawning performance were observed, except from a gradual reduction in fecundity.

The spawning kinetics of gilthead seabream during both years were typical of cultured fish (Mylonas et al. 2011). Spawning began in early January, soon after the shortest day of the year, with an initially increasing trend in daily fecundity, while fertilization success was very high almost from the beginning of the spawning season. The values and variation from day-to-day obtained were typical of the species under culture conditions (García-Fernández et al. 2018), although the slight reduction in daily fecundity right before the onset of the fasting period observed in both monitored broodstocks in the main study (year 2) was unexpected. However, egg production and quality did not decrease during the 43 and 54-day fasting periods of the preliminary and the main study, respectively, suggesting that even long fasting periods during the spawning season do not affect the production of good quantity and quality eggs in gilthead seabream. In addition, 5-d larval survival was stable during and after fasting. The decreases in fecundity and hatching percentage observed during the postfasting period of the main study, could be due to the approaching end of the spawning period, rather than the effect of fasting. As mentioned above, the fasting period in the main study started later than in the preliminary study, and it was closer to the end of the spawning season. Reduced egg quality towards the end of the reproductive season is common in aquaculture and has been shown both in gilthead seabream (Jerez et al. 2012) and in other sparids, such as the red porgy (Pagrus pagrus) (Mylonas et al. 2004). In fact, gilthead seabream fecundity in our facilities exhibits a decreasing trend for at least three weeks 
to a month before the end of the spawning period (Karamanlidis et al. 2017). Restriction or deprivation of feed in other species during vitellogenesis has been suggested to result in improved, instead of deteriorated, gamete quality (Reading et al. 2018). Also, in prepubertal male European seabass (Dicentrarchus labrax), it has been shown that feed restriction six months before reaching puberty, led to increases, instead of decreases, in some sperm motility parameters (Escobar et al. 2014). On the other hand, in the female European seabass restricted diets with half rations compared to controls, fed to fish 6 months before spawning led to decreased fecundity and hatching percentage, without affecting vitellogenesis and vitellogenin plasma levels (Cerdá et al. 1994a). The negative results of feed restriction in the latter study could be due to the restriction in feeding during the very important period of vitellogenesis in that species, and not simply during the spawning season.

Spawning is an energy and nutrient demanding process and observations of loss of weight after spawning indicate that feed alone cannot cover the energy and nutrient requirements of spawning fish (Tocher 2010). The monitored gilthead seabream were fed to apparent satiation on a commercial broodstock diet, and presumably they had built up adequate nutrient reserves prior to being subjected to feed deprivation. Feed deprived gilthead seabream continued to spawn without any significant negative effects on fecundity or egg quality. The significant reduction of crude protein concentration in maternal muscle and crude lipid concentration in liver coupled with the lower HSI indicate that muscle protein and liver fat were the main energy and nutrient sources utilized in fasted gilthead seabream during spawning. Perivisceral and peritoneal fat, which were not measured in the present investigation, could be additional sources. On the other hand, maternal muscle fat and liver proteins appeared to cover a minor portion of the demands. The reduction in the concentration of muscle crude protein and liver crude fat was counterbalanced by an increase in moisture concentration to maintain cellular volume. In a similar study, gilthead seabream fed on main ration during spawning did not deplete muscle proteins (Harel and Tandler 1994) and apparently, protein demands were covered by the diet; further, fat concentration in muscle decreased, which was not observed in the feed deprived seabream of the present study. It appears that gilthead seabream utilizes different nutrient reserves for maturing oocytes and for maintenance depending on their nutritional status, body reserves and the availability of feed. It is likely that in our study the fish undergo the third phase of fasting, a shift to protein mobilization as the main energy source, after a first short transient phase and a second fat oxidation phase (Bar 2014). Fasting had no effect on crude ash concentration in muscle, liver and gonads, apparently due to its minor influence on the mineral pool and the uptake of minerals from the rearing water. In general, the fatty acid profiles of muscle and liver lipids were similar prior to and after fasting. A reduction in $\Sigma \omega-6$ fatty acids in the muscle which is in line with the observation in sharpsnout seabream (Diplodus puntazzo) (Rondán et al. 2004) and an increase in $\Sigma \omega-6$ fatty acids in the liver were observed. Despite the statistically significant differences, their numerical differences appear to be small to have a biological significance.

Fasting reduced the crude protein concentration in gonads, as well as gonad size in terms of absolute weight and GSI. At the same time, the fecundity and proximate composition and quality of eggs were not affected. A confounding effect of time and fish physiology may exist as the reproduction season was advancing. Apart from the reduced crude proteins and subsequent water increase, no substantial effect of fasting was observed in crude lipids or fatty acids in gonads. Minor differences were observed in the gonadal fatty acid profiles of starved and fed fish, indicating adequate lipid reserves and non preferential use of any fatty acid. Since a fully-fed control group throughout the experiment was not considered necessary to examine the main hypothesis of the study, we do not have available data to confirm the above claims and exclude any confounding effects of the reproductive cycle of gilthead seabream. It is evident from the fasting and post fasting comparison, however, that gonadal development cannot be arrested by fasting, and the produced eggs are of similar quality in terms of fertilization, embryonic development and early larval survival.

The egg proximate composition was maintained unchanged without any apparent effect of feed deprivation in crude protein, crude lipid, crude ash, moisture and energy density. The reduction of crude protein in the ovaries did not influence the crude protein concentration in the eggs. This may imply that not all ovary tissues are directed into eggs or if there was an effect this was not detectable due to the big difference in crude protein concentration between ovaries (c.a. $20 \%$ ) and eggs (c.a. $3.8 \%$ ), potential homeostatic mechanisms may have maintained the crude protein concentration in eggs despite the reduction of crude protein in the ovaries. In general, fish maintain egg quality under limiting resources. In red seabream (Pagrus major) and Nile tilapia (Oreochromis niloticus), the protein content of the diet did not affect egg quality (Watanabe et al. 1984) while in three-spined sticklebacks (Gasterosteus aculeatus) the ration size (Fletcher and Wootton 1995) and in Nile tilapia feed deprivation also did not affect egg quality (Lupatsch et al. 2010). Still, it is generally agreed that diet composition affects the quantity and quality of eggs produced, and these reproduction parameters are highly influenced by nutrients such as essential fatty acids and a-tocopherol (Bell et al. 1997; Izquierdo et al. 2001; Watanabe and Vassallo-Agius 2003). Fish with long vitellogenic periods, e.g. salmonids or moronids such as European seabass, need to receive an adequate feed for a longer period prior to spawning, compared to fish with short vitellogenic periods, such as gilthead seabream. On the other hand, the latter may by more sensitive to qualitative and quantitative changes during the spawning season. Yet, it appears that gilthead seabream can build up adequate energy and protein reserves during the ovarian growth phase, and feed restriction for many weeks within the spawning period has no detectable effects on egg production and quality. Past data reporting that feed consumption decreases around the onset of spawning (Kadmon et al. 1985), may suggest that gilthead seabream can cope well under feed restriction during spawning.

As far as feed management is concerned, fasting during the spawning phase, if needed for management purposes, might be a better option than the provision of a deficient or imbalanced diet in certain nutrients. A decisive factor in the influence of fasting or feed restriction on reproductive performance is the timing of feed deprivation and the physiological state of fish up to that point. So it is probably more important to provide optimal nutrition throught the year before the reproductive season when the animals are building their body reserves, as well as during the extended process of vitellogenesis, rather than during spawning. Therefore, other husbandry parameters, such as stocking density, water quality, lack of disturbances and other welfare aspects, may be more important to reproductive performance than feeding to apparent satiation during the spawning period.

\section{Declarations}

Funding: The study was supported by an internal program (GnRHa implants, 60.70101) from the Institute of Marine Biology, Biotechnology and Aquaculture of the Hellenic Center for Marine Research to CCM. 
Conflicts of interest/Competing interests: The authors declare no conflict of interest.

Ethics approval: Ethical approval for the study was obtained by the relevant Greek authorities (National Veterinary Services) under the license No 255356 $(\mathrm{A} \triangle \mathrm{A}: 6 \wedge \mathrm{I} 17 \wedge \mathrm{K}-\Pi \wedge \Omega)$. All procedures involving animals were conducted in accordance to the "Guidelines for the treatment of animals in behavioral research and teaching" (Anonymous 1998), the Ethical justification for the use and treatment of fishes in research: an update (Metcalfe and Craig 2011) and the "Directive 2010/63/EU of the European parliament and the council of 22 September 2010 on the protection of animals used for scientific purposes" (EU 2010)

Data availability: The original data of the study are available on request.

Contributions: Constantinos C. Mylonas designed the experiment. The fish husbandry and sample collection were performed by Irini Sigelaki, Fabrizio Caruso and Maria Papadaki. Nutritional analyses were carried out by Stavros Chatzifotis and Abraham Gómez Gutiérrez. Data analysis was performed by Maria Papadaki, Fabrizio Caruso and Stavros Chatzifotis. The manuscript was written by Stavros Chatzifotis, Maria Papadaki and Constantinos C. Mylonas. All authors read and approved the final manuscript.

\section{References}

1. Almansa E (2001) Lipid and fatty acid composition of female gilthead seabream during their reproductive cycle: effects of a diet lacking n-3 HUFA. J Fish Biol 59:267-286. doi:10.1111/j.1095-8649.2001.tb00129.x

2. Anonymous (1998) Guidelines for the treatment of animals in behavioural research and teaching. Anim Behav 55:251-257

3. AOAC (1989) Official Methods and Recommended Practices of the Americal Oil Chemists' Society. 4th ed Americal Oil Chemists' Society Illinois

4. Bar N (2014) Physiological and hormonal changes during prolonged starvation in fish. Can J Fish Aquat Sci 71:1447-1458

5. Bell JG, Farndale BM, Bruce M, Navas JM, Carrillo M (1997) Effects of broodstock dietary lipid on fatty acid compositions of eggs from sea bass (Dicentrarchus labrax). Aquaculture 149:107-119

6. Cerdá J, Carrillo M, Zanuy S, Ramos J (1994a) Effect of food ration on estrogen and vitellogenin plasma levels, fecundity and larval survival in captive sea bass, Dicentrarchus labrax. preliminary observations. Aquat Living Resour 7:255-266

7. Cerdá J, Carrillo M, Zanuy S, Ramos J, de la Higuera M (1994b) Influence of nutritional composition of diet on sea bass, Dicentrarchus labrax L., reproductive performance and egg and larval quality. Aquaculture 128:345-361 doi. Doi 10.1016/0044-8486(94)90322-0

8. Escobar S, Felip A, Salah M, Zanuy S, Carrillo M (2014) Long-term feeding restriction in prepubertal male sea bass (Dicentrarchus labrax L.) increases the number of apoptotic cells in the testis and affects the onset of puberty and certain reproductive parameters. Aquaculture 433:504-512. doi:10.1016/j.aquaculture.2014.07.008

9. EU (2010) Directive 2010/63/EU of the European parliament and the council of 22 September 2010 on the protection of animals used for scientific purposes. Official Journal of the European Union L 276:33-79

10. Fernández-Palacios H, Norberg B, Izquierdo M, Hamre K (2011) Effects of broodstock diet on eggs and larvae. In: Holt J (ed) Larval Fish Nutrition. WileyBlackwell, Oxford, pp 153-181

11. Fletcher DA, Wootton RJ (1995) A hierarchical response to differences in ration size in the reproductive performance of female three-spined sticklebacks. J Fish Biol 46:657-668

12. García-Fernández C, Sánchez JA, Blanco G (2018) Early assessment of gilthead sea bream (Sparus aurata) spawning dynamics by mini-broodstocks. Aquac Res 49:36-47. doi:10.1111/are.13430

13. Harel M, Tandler A (1994) The kinetics of nutrient incorporation into body tissues of gilthead seabream (Sparus aurata) females and the subsequent effects on egg composition and egg quality. Br J Nutr 72:45-58

14. Higuchi K, Yoshida K, Gen K, Matsunari H, Takashi T, Mushiake K, Soyano K (2018) Effect of long-term food restriction on reproductive performances in female yellowtail, Seriola quinqueradiata. Aquaculture 486:224-231. doi:10.1016/j.aquaculture.2017.12.032

15. Higuchi K, Yoshida K, Gen K, Nyuji M, Takashi T, Mushiake K, Soyano K (2017) Effect of timing of restricted feeding on sexual maturation in female yellowtail, Seriola quinqueradiata. Aquaculture 479:609-615. doi:10.1016/j.aquaculture.2017.06.039

16. Izquierdo MS, Fernández-Palacios H, Tacon AGJ (2001) Effect of broodstock nutrition on reproductive performance of fish. Aquaculture 197:25-42 doi. Doi 10.1016/S0044-8486(01)00581-6

17. Jerez S, Rodríguez C, Cejas JR, Martín MV, Bolaños A, Lorenzo A (2012) Influence of age of female gilthead seabream (Sparus aurata L.) broodstock on spawning quality throughout the reproductive season. Aquaculture 350-353:54-62. doi:10.1016/j.aquaculture.2012.04.018

18. Kadmon G, Gordin H, Yaron Z (1985) Breeding-related growth of captive Sparus aurata (Teleostei, Perciformes) Aquaculture 46:299-305

19. Karamanlidis D, Sigelaki I, Papadaki M, Fakriadis I, Mylonas CC Evolution of sex ratio and egg production in a population of gilthead seabream (Sparus aurata) over the course of five reproductive seasons. In: Aquaculture Europe 2017, Dubrovnik, Croatia, 17-20 October, 2017 2017. European Aquaculture Society

20. Lupatsch I, Deshev R, Magen I (2010) Energy and protein demands for optimal egg production including maintenance requirements of female tilapia Oreochromis niloticus. Aquac Res 41:763-769. doi:10.1111/j.1365-2109.2009.02229.x

21. Metcalfe JD, Craig JF (2011) Ethical justification for the use and treatment of fishes in research: an update. J Fish Biol 78:393-394. doi:10.1111/j.10958649.2010.02900.x

22. Mylonas CC, Papadaki M, Pavlidis M, Divanach P (2004) Evaluation of egg production and quality in the Mediterranean red porgy (Pagrus pagrus) during two consecutive spawning seasons. Aquaculture 232:637-649 doi. Doi 10.1016/S0044-8486(03)00534-9

Page 6/13 
23. Mylonas CC, Zohar Y, Pankhurst NW, Kagawa H (2011) Reproduction and broodstock management. In: Pavlidis M, Mylonas CC (eds) Sparidae: Biology and Aquaculture of Gilthead Seabream and Related Species. Blackwell Science Publishers, London, pp 95-131

24. Panini E, Mylonas CC, Zanuy S, Carrillo M, Ramos J, Bruce M (2001) Incubation of embryos and larvae of marine fish using microtiter plates. Aquacult Int 9:189-196

25. Papadaki M, Papadopoulou M, Siggelaki I, Mylonas CC (2008) Egg and sperm production and quality of sharpsnout sea bream (Diplodus puntazzo) in captivity. Aquaculture 276:187-197. doi:10.1016/j.aquaculture.2008.01.033

26. Perez KO, Fuiman LA (2015) Maternal diet and larval diet influence survival skills of larval red drum Sciaenops ocellatus. J Fish Biol 86:1286-1304. doi:10.1111/jfb.12637

27. Reading B, Andersen L, Ryu Y-W, Mushirobira Y, Todo T, Hiramatsu N (2018) Oogenesis and Egg Quality in Finfish: Yolk Formation and Other Factors Influencing Female Fertility. Fishes 3 doi:10.3390/fishes3040045

28. Roa J, Garcia-Galiano D, Castellano JM, Gaytan F, Pinilla L, Tena-Sempere M (2010) Metabolic control of puberty onset: new players, new mechanisms. Mol Cell Endocrinol 324:87-94. doi:10.1016/j.mce.2009.12.018

29. Rondán M, Hernández MD, Egea MA, García B, Rueda FM, Martínez FJ (2004) Effect of feeding rate of fatty acid composition of sharpsnout seabream (Diplodus puntazzo). Aquacult Nutr 10:301-307

30. Scabini V, Fernández-Palacios H, Robaina L, Kalinowski T, Izquierdo MS (2011) Reproductive performance of gilthead seabream (Sparus aurata L., 1758) fed two combined levels of carotenoids from paprika oleoresin and essential fatty acids. Aquacult Nutr 17:304-312. doi:10.1111/j.13652095.2010.00766.x

31. Tandler A, Harel M, Koven WM, Kolkovski S (1995) Broodstock and larvae nutrition in gilthead seabream Sparus aurata - new findings on its mode of involvement in improving growth, survival and swimbladder inflation. Isr J Aquac 47:95-111

32. Tocher DR (2010) Metabolism and Functions of Lipids and Fatty Acids in Teleost Fish. Rev Fish Sci 11:107-184. doi:10.1080/713610925

33. Watanabe T, Arakawa T, Kitajima C, Fujita S (1984) Effect of nutritional quality of broodstock diets on reproduction of red sea bream. Bull Jpn Soc Sci Fish 50:495-501

34. Watanabe T, Vassallo-Agius R (2003) Broodstock nutrition research on marine finfish in Japan. Aquaculture 227:35-61

\section{Tables}

Table 1. Biometric data (mean \pm SD) of the breeders in two hatchery-produced gilthead seabream broodstocks used in the preliminary (year 1 ) and main studies (year 2). The reduction in the number of females was done to decrease the total biomass and maintain an appropriate stocking density in the spawning tanks (Mylonas et al. 2011).

\begin{tabular}{|llllll|}
\hline & Broodstock 1 & Broodstock 2 & & & \\
\hline Preliminary study (year 1) & Females & Males & Females & Males & \\
\hline & (n) & 23 & 3 & 19 & 4 \\
\hline & body weight (kg) & $1.30 \pm 0.27$ & $1.17 \pm 0.23$ & $1.52 \pm 0.22$ & $1.23 \pm 0.27$ \\
\hline Main study (year 2) & Females & Males & Females & Males & \\
\hline & (n) & 14 & 3 & 13 & 3 \\
& body weight $(\mathbf{k g})$ & $1.69 \pm 0.45$ & $1.33 \pm 0.21$ & $1.70 \pm 0.32$ & $1.30 \pm 0.10$ \\
\hline
\end{tabular}

Table 2. Mean ( \pm SD) gilthead seabream (Sparus aurata) biometrics of female breeder during the spawning period, before and after a fasting period of 54 days. Asterisks denote statistically significant differences between fed and starved fish (one-way ANOVA, Tukey's HSD, P $\leq 0.05$ ).

\begin{tabular}{|c|c|c|c|c|}
\hline \multirow[b]{2}{*}{ Total length (cm) } & \multicolumn{2}{|c|}{ Before fasting } & \multicolumn{2}{|c|}{ After fasting } \\
\hline & 40.3 & $(2.1)^{\star}$ & 38.2 & $(4.8)$ \\
\hline Body weight (kg) & 1.89 & $(0.21)^{*}$ & 1.44 & $(0.18)$ \\
\hline Liver weight (g) & 33.7 & $(4.4)^{\star}$ & 13.1 & $(4.8)$ \\
\hline Gonad weight (g) & 146.8 & $(67.2) *$ & 79.6 & $(36.9)$ \\
\hline GSI (\%) & 7.6 & (2.8) & 5.7 & $(2.9)$ \\
\hline HSI (\%) & 1.8 & $(0.2)^{\star}$ & 0.9 & $(0.3)$ \\
\hline
\end{tabular}




\begin{tabular}{|c|c|c|c|c|c|c|c|c|c|c|c|c|c|c|c|}
\hline \multirow{3}{*}{$\begin{array}{l}\text { Fatty } \\
\text { acid }\end{array}$} & \multicolumn{4}{|l|}{ Muscle } & \multicolumn{4}{|l|}{ Liver } & \multicolumn{4}{|c|}{ Gonads } & \multicolumn{3}{|l|}{ Eggs } \\
\hline & \multicolumn{2}{|c|}{ Fed $(n=4)$} & \multicolumn{2}{|c|}{ Fasted $(n=4)$} & \multicolumn{2}{|c|}{ Fed $(n=4)$} & \multicolumn{2}{|c|}{ Fasted $(n=4)$} & \multicolumn{2}{|c|}{ Fed $(n=4)$} & \multicolumn{2}{|c|}{ sted $(n=4)$} & \multirow{2}{*}{$\begin{array}{l}\begin{array}{l}\text { Pre- } \\
\text { fasting } \\
(n=12)\end{array} \\
5.8\end{array}$} & \multicolumn{2}{|c|}{ During Fasting. } \\
\hline & 6.81 & $(0.23)$ & 6.77 & (1.33) & 7.07 & $(1.78)$ & 6.75 & $(0.98)$ & 5.38 & $(1.36)$ & 5.81 & $(0.70)$ & & (1.97) & 5.44 \\
\hline C15:0 & 0.35 & $(0.04)$ & 0.35 & $(0.07)$ & 0.54 & $(0.16)$ & 0.47 & $(0.11)$ & 0.40 & $\begin{array}{l}(0.01) \\
a\end{array}$ & 0.42 & $\begin{array}{l}(0.01) \\
\mathrm{b}\end{array}$ & 0.20 & $\begin{array}{l}(0.02) \\
a\end{array}$ & 0.22 \\
\hline C16:0 & 20.89 & $(0.88)$ & 21.01 & (3.19) & 25.20 & $\begin{array}{l}(0.14) \\
\mathrm{a}\end{array}$ & 24.29 & $\begin{array}{l}(0.20) \\
\mathrm{b}\end{array}$ & 23.23 & $(2.43)$ & 23.57 & $(2.97)$ & 15.89 & $\begin{array}{l}(1.14) \\
\text { ac }\end{array}$ & 18.14 \\
\hline C17:0 & 0.54 & $(0.10)$ & 0.55 & $(0.13)$ & 0.84 & $(0.07)$ & 0.82 & $(0.12)$ & 0.71 & $(0.08)$ & 0.74 & $(0.06)$ & 0.50 & $\begin{array}{l}(0.13) \\
a\end{array}$ & 0.40 \\
\hline C18:0 & 3.46 & $(0.09)$ & 3.45 & $(0.39)$ & 3.98 & $\begin{array}{l}(0.30) \\
a\end{array}$ & 4.03 & $\begin{array}{l}(0.53) \\
b\end{array}$ & 4.12 & $(0.28)$ & 4.04 & $(0.32)$ & 3.80 & $\begin{array}{l}(0.23) \\
a\end{array}$ & 3.31 \\
\hline C20:0 & 0.09 & $(0.02)$ & 0.08 & $(0.01)$ & 0.09 & $(0.03)$ & 0.08 & $(0.03)$ & 0.13 & $(0.03)$ & 0.12 & $(0.04)$ & 0.05 & $\begin{array}{l}(0.01) \\
a\end{array}$ & 0.06 \\
\hline C24:0 & 0.29 & $(0.01)$ & 0.29 & $(0.11)$ & 0.15 & $(0.02)$ & 0.15 & $(0.02)$ & 0.21 & $(0.03)$ & 0.2 & $(0.06)$ & 0.2 & $(0.04)$ & 0.18 \\
\hline$\Sigma$ SFA & 32.42 & $(0.83)$ & 32.52 & $(4.93)$ & 37.87 & (3.35) & 36.59 & (3.41) & 34.18 & (3.67) & 34.91 & (3.61) & 26.43 & $\begin{array}{l}(1.12) \\
a\end{array}$ & 27.75 \\
\hline $\begin{array}{l}\text { C14:1 } \\
\omega-5\end{array}$ & 0.34 & $(0.08)$ & 0.32 & $(0.15)$ & 0.2 & $(0.07)$ & 0.18 & (0.09) & 0.17 & $(0.06)$ & 0.18 & $(0.02)$ & 0.18 & $\begin{array}{l}(0.09) \\
a b\end{array}$ & 0.22 \\
\hline $\begin{array}{l}\text { C16:1 } \\
\omega-4\end{array}$ & n.i. & n.i. & n.i. & n.i & n.i. & n.i. & n.i. & n.i. & n.i. & n.i. & n.i. & n.i. & 1.21 & $\begin{array}{l}(0.03) \\
\text { ac }\end{array}$ & 1.41 \\
\hline $\begin{array}{l}\text { C16:1 } \\
\omega-5\end{array}$ & n.i. & n.i. & n.i. & n.i & n.i. & n.i. & n.i. & n.i. & n.i. & n.i. & n.i. & n.i. & 0.31 & $\begin{array}{l}(0.03) \\
\mathrm{ac}\end{array}$ & 0.37 \\
\hline $\begin{array}{l}\text { C16:1 } \\
\omega-7\end{array}$ & 6.36 & $(1.45)$ & 6.19 & $(0.66)$ & 8.09 & $(0.84)$ & 8.15 & $(0.69)$ & 6.79 & $(0.94)$ & 7.18 & $(1.13)$ & 4.07 & $\begin{array}{l}(0.30) \\
a\end{array}$ & 4.95 \\
\hline $\begin{array}{l}\text { C18:1 } \\
\omega-4\end{array}$ & n.i. & n.i & n.i. & n.i. & n.i. & n.i. & n.i. & $(0.09)$ & n.i. & n.i. & n.i. & n.i. & 0.03 & $(0.00)$ & 0.07 \\
\hline $\begin{array}{l}\text { C18:1 } \\
\omega-7\end{array}$ & 0.38 & $(0.05)$ & 0.37 & $(0.14)$ & 0.3 & $(0.15)$ & 0.3 & $(1.72)$ & 0.25 & $(0.04)$ & 0.25 & $(0.03)$ & 0.18 & $(0.09)$ & 0.13 \\
\hline $\begin{array}{l}\text { C18:1 } \\
\omega-9\end{array}$ & 27.78 & $(1.06)$ & 27.7 & $(4.22)$ & 29.37 & (1.54) & 29.63 & $(0.30)$ & 22.31 & $(0.02)^{a}$ & 22.16 & $(0.01)^{b}$ & 24.17 & $\begin{array}{l}(1.22) \\
\mathrm{a}\end{array}$ & 22.56 \\
\hline C20:1 n-7 & n.i. & n.i. & n.i. & n.i. & n.i. & n.i. & n.i. & n.i. & n.i. & n.i. & n.i. & n.i. & 0.43 & $(0.02)$ & 0.37 \\
\hline $\begin{array}{l}C 20: 1 \\
\omega-9\end{array}$ & 2.56 & $(0.08)$ & 2.56 & (1.10) & 1.27 & $(0.50)$ & 1.37 & $(0.30)$ & 0.72 & $(0.12)$ & 0.67 & $(0.22)$ & 0.64 & $\begin{array}{l}(0.04) \\
a\end{array}$ & 0.75 \\
\hline $\begin{array}{l}\text { C24:1 } \\
\omega-9\end{array}$ & 0.53 & $(0.07)$ & 0.52 & $(0.23)$ & 0.2 & $(0.09)$ & 0.21 & $(0.14)$ & 0.33 & $(0.06)$ & 0.31 & $(0.11)$ & 0.24 & $\begin{array}{l}(0.02) \\
a\end{array}$ & 0.23 \\
\hline$\Sigma$ MUFA & 37.94 & $(2.67)$ & 37.64 & $(5.58)$ & 39.44 & (1.39) & 39.84 & $(1.51)$ & 30.57 & $(0.05)^{a}$ & 30.74 & $(0.12)^{b}$ & 31.46 & $\begin{array}{l}(0.16) \\
a\end{array}$ & 31.06 \\
\hline $\begin{array}{l}\text { C18:2 } \\
\omega-6\end{array}$ & 9.88 & $(0.13)$ & 9.86 & $(0.67)$ & 9.34 & $(0.29)$ & 9.34 & $(0.61)$ & 9.29 & $(0.53)$ & 9.19 & $(0.86)$ & 12.34 & $\begin{array}{l}(1.09) \\
a\end{array}$ & 9.73 \\
\hline $\begin{array}{l}\text { C18:3 } \\
\omega-6\end{array}$ & 0.25 & $(0.03)$ & 0.25 & $(0.04)$ & 0.37 & $(0.16)$ & 0.37 & $(0.13)$ & 0.37 & $(0.13)$ & 0.37 & $(0.05)$ & 0.30 & $\begin{array}{l}(0.05) \\
a\end{array}$ & 0.23 \\
\hline $\begin{array}{l}\text { C20:2 } \\
\omega-6\end{array}$ & 0.35 & $(0.05)$ & 0.34 & $(0.09)$ & 0.23 & $(0.04)$ & 0.23 & $(0.16)$ & 0.26 & $(0.11)$ & 0.21 & $(0.07)$ & 0.00 & $(0.00)$ & 0.00 \\
\hline $\begin{array}{l}C 20: 4 \\
\omega-6\end{array}$ & $0.74^{a}$ & $(0.01)$ & 0.75 & $\begin{array}{l}(0.01) \\
\mathrm{b}\end{array}$ & 0.7 & $(0.17)$ & 0.72 & $(0.11)$ & 0.9 & $(0.22)$ & 0.84 & $(0.37)$ & 0.77 & $(0.05)$ & 0.7 \\
\hline $\begin{array}{l}\sum \omega-6 \\
\text { PUFA }\end{array}$ & 11.22 & $(0.01)^{a}$ & 11.20 & $(0.01)^{b}$ & $10.64^{a}$ & $(0.31)$ & $10.66^{b}$ & $(0.71)$ & 10.83 & $(0.61)$ & 10.61 & $(0.93)$ & $13.41^{\mathrm{a}}$ & $(1.02)$ & $10.66^{b}$ \\
\hline $\begin{array}{l}\text { C18:2 } \\
\omega-9\end{array}$ & n.i. & n.i. & n.i. & n.i. & n.i. & n.i. & n.i. & n.i. & n.i. & n.i. & n.i. & n.i. & 0.22 & $\begin{array}{l}(0.02) \\
a\end{array}$ & 0.16 \\
\hline
\end{tabular}




\begin{tabular}{|c|c|c|c|c|c|c|c|c|c|c|c|c|c|c|c|}
\hline $\begin{array}{l}\text { C20:2 } \\
\omega-9\end{array}$ & n.i. & n.i. & n.i. & n.i. & n.i. & n.i. & n.i. & n.i. & n.i. & n.i. & n.i. & n.i. & $0.27^{a}$ & $(0.01)$ & $0.23^{b}$ \\
\hline $\begin{array}{l}\text { C18:3 } \\
\omega-3\end{array}$ & 1.77 & $(0.03)^{a}$ & 1.73 & $\begin{array}{l}(0.01) \\
b\end{array}$ & $1.37^{\mathrm{a}}$ & $(0.12)$ & $1.34^{b}$ & $(0.07)$ & 1.4 & $(0.06)$ & 1.4 & $(0.26)$ & 1.99 & $\begin{array}{l}(0.24) \\
a\end{array}$ & 1.29 \\
\hline $\begin{array}{l}C 20: 3 \\
\omega-3\end{array}$ & 0.17 & $(0.01)$ & 0.17 & $(0.04)$ & 0.14 & $(0.05)$ & 0.15 & $(0.22)$ & 0.19 & $(0.06)$ & 0.16 & $(0.06)$ & n.i. & n.i. & n.i. \\
\hline $\begin{array}{l}\text { C20:3 } \\
\omega-9\end{array}$ & n.i. & n.i. & n.i. & n.i & n.i. & n.i. & n.i. & n.i. & n.i. & n.i. & n.i. & n.i. & 0.24 & $(0.03)$ & 0.29 \\
\hline $\begin{array}{l}\text { C20:4 } \\
\omega-3\end{array}$ & 2.41 & $(0.02)$ & 2.42 & (1.18) & 1.14 & $(0.41)$ & 1.22 & $(0.40)$ & 0.82 & $(0.14)$ & 0.75 & $(0.22)$ & 0.61 & $(0.08)$ & 0.6 \\
\hline $\begin{array}{l}\text { C20:5 } \\
\omega-3\end{array}$ & 4.06 & $(0.29)$ & 4.08 & $(0.24)$ & 2.81 & $(0.58)$ & 2.98 & $(0.20)$ & 5.32 & $(0.08)^{a}$ & 5.20 & $(0.05)^{b}$ & 4.73 & $\begin{array}{l}(0.39) \\
a\end{array}$ & 3.99 \\
\hline $\begin{array}{l}C 22: 5 \\
\omega-3\end{array}$ & 1.94 & (1.32) & 2 & $(0.39)$ & 1.01 & $(0.38)$ & 1.06 & $(0.19)$ & 2.08 & $(0.17)$ & 2.05 & $(0.66)$ & 1.94 & $\begin{array}{l}(0.16) \\
a\end{array}$ & 1.90 \\
\hline $\begin{array}{l}C 22: 6 \\
\omega-3\end{array}$ & 8.05 & $(1.32)$ & 8.23 & $(2.16)$ & 5.57 & $(2.21)$ & 6.15 & (1.15) & 14.63 & (2.64) & 14.18 & $(2.65)$ & 15.33 & $\begin{array}{l}(1.55) \\
a\end{array}$ & 17.70 \\
\hline $\begin{array}{l}\sum \omega-3 \\
\text { PUFA }\end{array}$ & 18.41 & (1.76) & 18.64 & (1.15) & 12.05 & (3.18) & 12.9 & (1.75) & 24.42 & (3.15) & 23.74 & (3.59) & 24.61 & $\begin{array}{l}(1.57) \\
a\end{array}$ & 25.48 \\
\hline$E P A / D H A$ & 0.51 & $(1.84)$ & 0.5 & $(0.08)$ & 0.53 & $\begin{array}{l}(0.09) \\
a\end{array}$ & 0.51 & $\begin{array}{l}(0.04) \\
b\end{array}$ & 0.37 & $(0.06)^{a}$ & 0.38 & $(0.03)^{b}$ & 0.31 & $\begin{array}{l}(0.04) \\
a\end{array}$ & 0.23 \\
\hline$E P A / A R A$ & 5.48 & $(0.03)^{a}$ & 5.51 & $(0.01)^{b}$ & 4.08 & $\begin{array}{l}(0.03) \\
a\end{array}$ & 4.20 & $\begin{array}{l}(0.05) \\
b\end{array}$ & 6.26 & $(0.04)^{a}$ & 6.62 & $(0.07)^{b}$ & 0.16 & $\begin{array}{l}(0.16) \\
a\end{array}$ & 0.17 \\
\hline$D H A / A R A$ & 10.80 & $(0.04)^{a}$ & 10.99 & $(0.03)^{b}$ & 7.82 & $(0.36)$ & 8.38 & $(0.47)$ & 17.55 & (7.62) & 18.56 & (4.99) & 20.06 & (1.93) & 25.51 \\
\hline
\end{tabular}

Table 4. Mean ( \pm SD) proximate composition of gilthead seabream (Sparus aurata) eggs from spawns obtained before, during and after fasting of two broodstocks (Pre-fasting, $n=12$; Fasting $n=16$; Post-fasting $n=10$ ). No statistically significant differences were observed among the three periods, in any of the measure parameters (one-way ANOVA, Tukey's HSD, P>0.05)

\begin{tabular}{|c|c|c|c|c|c|c|c|c|c|c|}
\hline & Mois & & $\begin{array}{l}\text { Protein } \\
\text { (\%) }\end{array}$ & & $\begin{array}{l}\text { Lipids } \\
\text { (\%) }\end{array}$ & & $\begin{array}{l}\text { Ash } \\
(\%)\end{array}$ & & $\begin{array}{l}\text { Energy } \\
(\mathrm{kJ} / \mathrm{g})\end{array}$ & \\
\hline Pre-fasting & 93.2 & $(0.43)$ & 3.91 & $(0.13)$ & 1.53 & $(0.10)$ & 1.21 & $(0.24)$ & 1.33 & $(0.05)$ \\
\hline Fasting & 93.0 & $(0.27)$ & 3.86 & $(0.06)$ & 1.42 & $(0.08)$ & 1.17 & $(0.07)$ & 1.35 & $(0.02)$ \\
\hline Post-fasting & 93.0 & $(0.13)$ & 3.83 & $(0.04)$ & 1.43 & $(0.43)$ & 1.21 & $(0.11)$ & 1.31 & $(0.01)$ \\
\hline
\end{tabular}

\section{Figures}


Broodstock 1

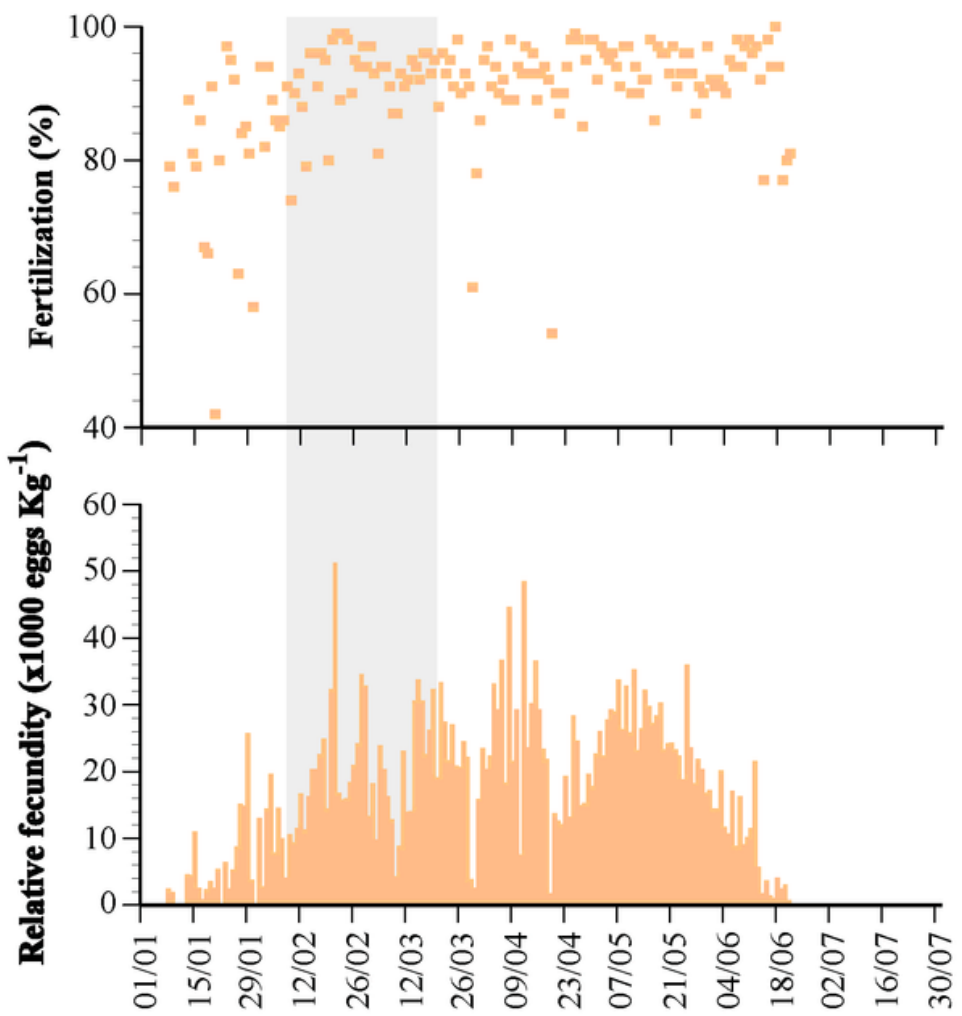

Date
Preliminary study (year 1)

Broodstock 2
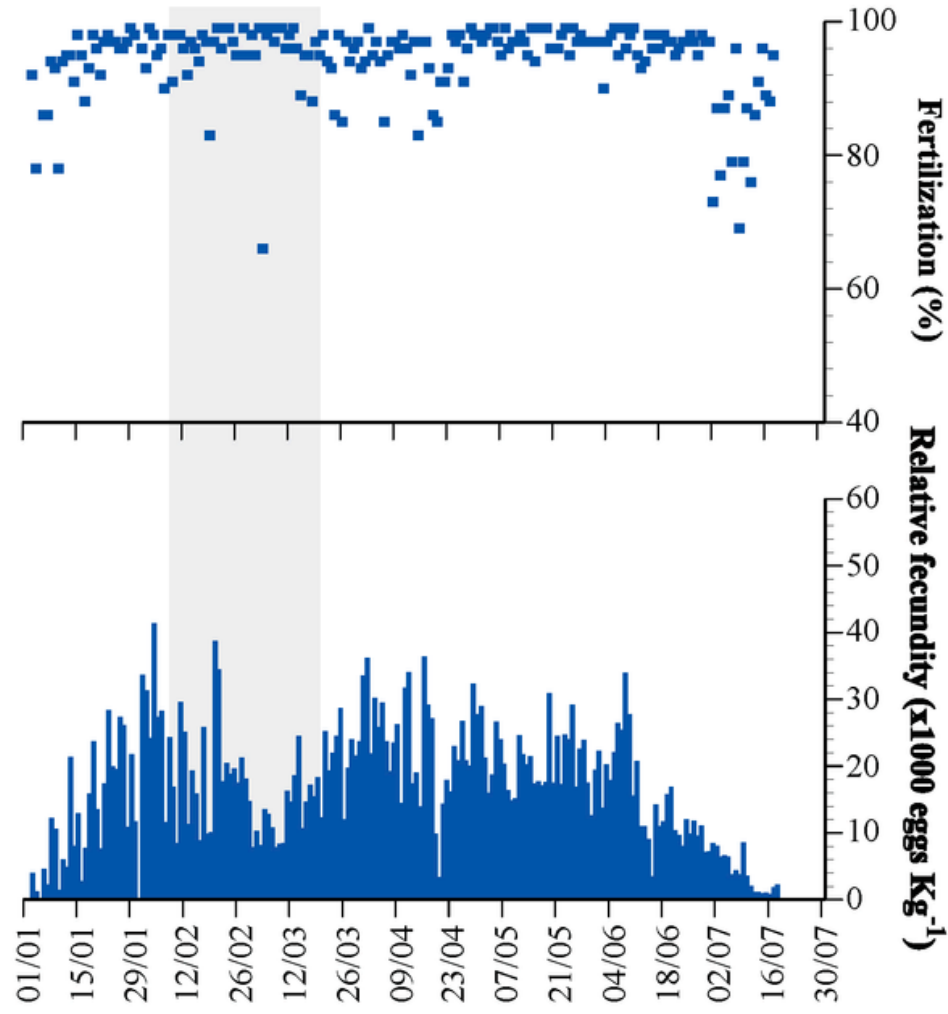

Date

Figure 1

Daily relative fecundity (x103 eggs Kg-1 female biomass) and fertilization success (\%), of gilthead seabream (Sparus aurata) broodstocks ( $\mathrm{n}=2$ ) during the preliminary study (year 1). The grey-shaded area marks the 43-day fasting period during the reproductive season. 


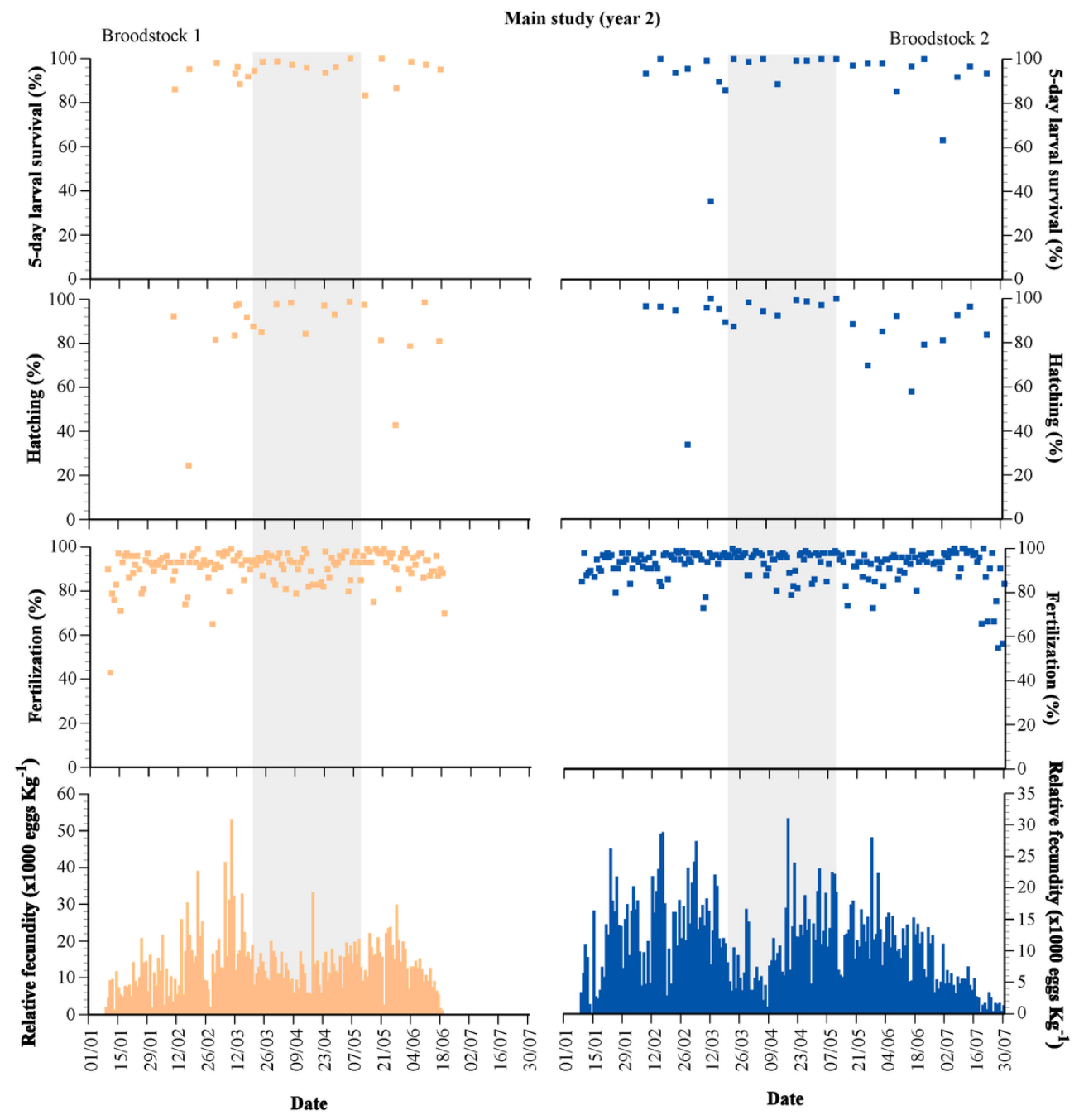

\section{Figure 2}

Daily relative fecundity (x103 eggs Kg-1 female biomass), fertilization, hatching and 5-day larval survival (\%) of gilthead seabream (Sparus aurata) broodstocks $(n=2)$ during the main study (year 2 ). The grey-shaded area marks the 54 -day fasting period during the reproductive season. 


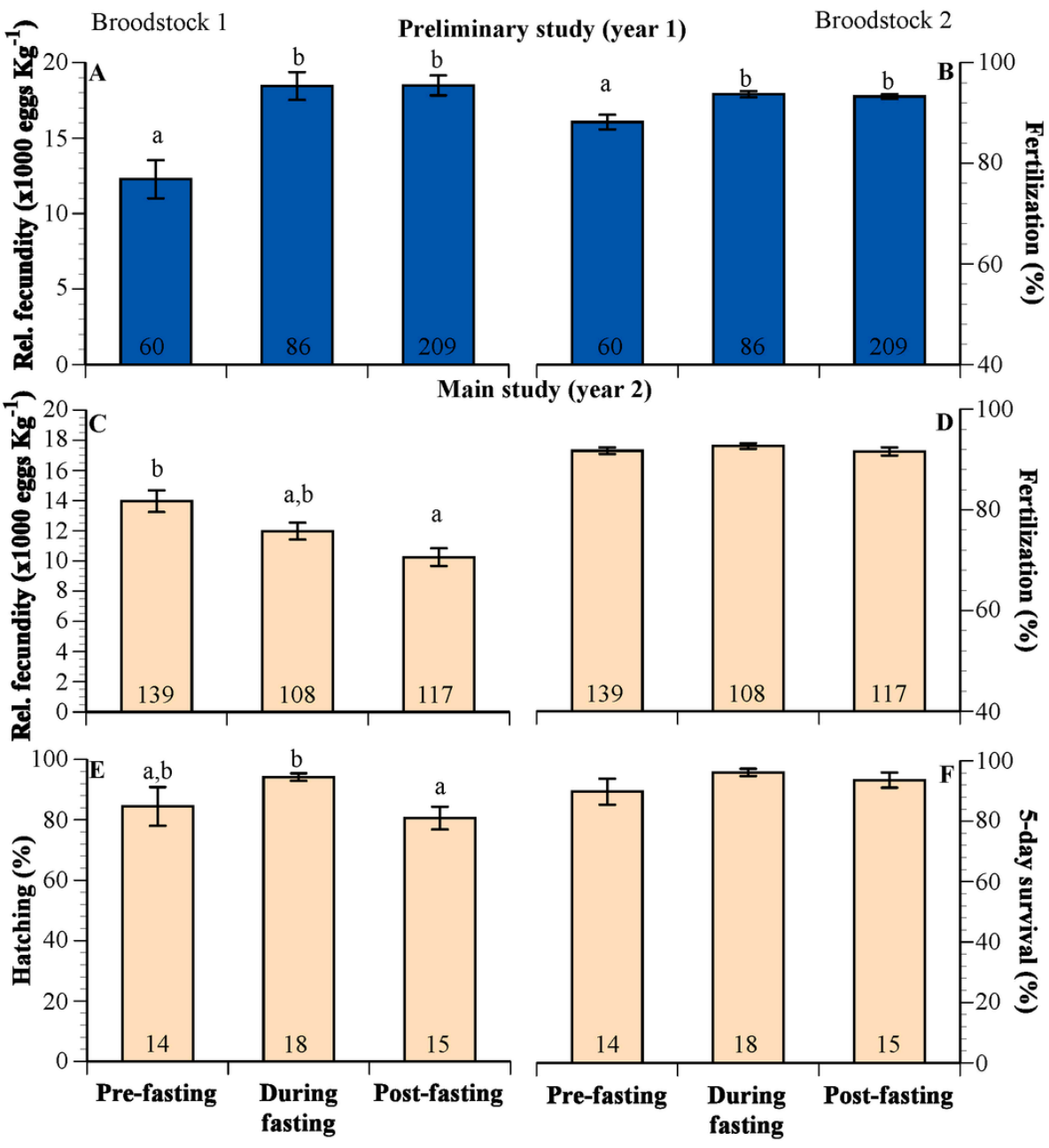

Sample time

Figure 3

Mean ( \pm S.E.M.) relative fecundity (A) and fertilization (B) of gilthead seabream (Sparus aurata) broodstocks $(n=2)$ before, during and after a 43 -day fasting within the spawing period in the preliminary study (year 1, blue bars, See Fig. 1). Mean ( \pm S.E.M.) relative fecundity (C), fertilization (D) hatching (E) and 5-day larval survival $(F)$ of gilthead seabream broodstocks $(n=2)$ before, during and after a 54-day fasting period within the spawning period in the main study (year 2, orange bars) (See Fig. 2). The numbers inside the bars indicate the number of daily spawns constituting the means, obtained from both replicated broodstocks. Significant differences among the pre-fasting, fasting and post-fasting periods within each year are indicated by different letter superscripts above the mean bars (ANOVA, Tukey's HSD, * $\mathrm{P}<0.05$ ). 


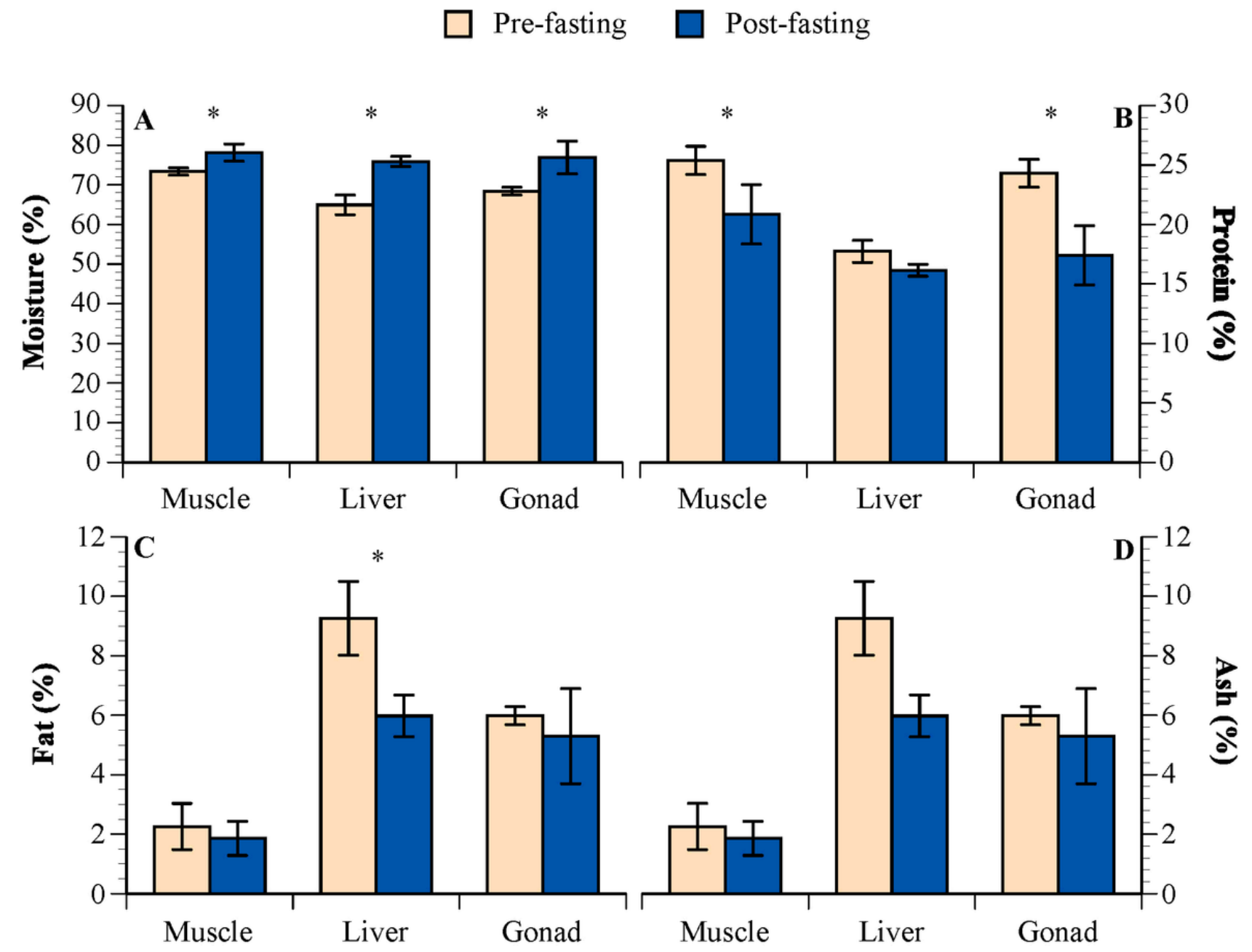

Figure 4

Mean ( $\pm S D$ ) proximate tissue composition of female gilthead seabream (Sparus aurata) breeders $(n=4)$ before and at the end of a 54 -day fasting period during the spawning season in the main study (year 2). Asterisks indicate significant differences between fed and fasted fish (ANOVA, Tukey's HSD, * $P$ < 0.05). 